\title{
PERBANDINGAN PERFORMA METODE KLASIFIKASI SVM, NEURAL NETWORK, DAN NAÏVE BAYES UNTUK MENDETEKSI KUALITAS PENGAJUAN KREDIT DI KOPERASI SIMPAN PINJAM
}

\author{
Iqbal Taufiq Ahmad Nur' ${ }^{1}$, Nanang Yudi Setiawan ${ }^{2}$, Fitra A. Bachtiar ${ }^{3}$ \\ 1,2,3Program Studi Sistem Informasi, Fakultas Ilmu Komputer, Universitas Brawijaya \\ Email: ${ }^{1}$ iqbaltaufiqan@ student.ub.ac.id, ${ }^{2}$ nanang@ub.ac.id, ${ }^{3}$ fitra.bachtiar@ub.ac.id
}

(Naskah masuk: 05 Desember 2018, diterima untuk diterbitkan: 01 Juli 2019)

\begin{abstract}
Abstrak
Mendeteksi kualitas kredit sejak dini merupakan satu tahapan penting yang wajib dilakukan oleh koperasi simpan pinjam guna meminimalisir adanya risiko kredit. Dalam penelitian ini, kami menggunakan tiga metode klasifikasi yaitu SVM, Neural Network, dan Nä̈ve Bayes untuk menemukan metode dengan performa yang paling baik dan optimal pada kasus pendeteksian kualitas kredit di koperasi simpan pinjam. Proses yang dilakukan adalah dengan mengimplementasikan data hasil pre processing menggunakan algoritme SVM, Neural Network, dan Nä̈ve Bayes dengan proses evaluasi menggunakan 5-fold cross validation. Hasil yang didapatkan adalah metode Neural Network menjadi metode dengan performa paling baik. Rerata tingkat akurasi yang dihasilkan sebesar $86,81 \%$, rerata precision sebesar 0,8194 , rerata recall sebesar 0,8236 , dan rerata nilai AUC sebesar 0,9158. Namun, waktu eksekusi yang dihasilkan algoritme Neural Network menjadikan algoritme ini sebagai algoritme paling lambat dibandingkan dengan dua metode lain. Nilai rerata waktu eksekusi dari metode Neural Network sebesar 3,058 detik, jauh lebih lama dibandingkan dua algoritme lain yang hanya berkisar pada nilai $0-1$ detik.
\end{abstract}

Kata kunci: risiko kredit, klasifikasi, SVM, Neural Network, Naive Bayes

\section{PERFORMANCE COMPARISON OF SVM, NEURAL NETWORK AND NAÏVE BAYES CLASSIFICATION METHOD FOR DETECTING THE QUALITY OF CREDIT APPLICATIONS IN KOPERASI SIMPAN PINJAM}

\begin{abstract}
Detecting credit quality at the early stage is an important step that must be done by koperasi simpan pinjam in order to minimize the credit risk. In this research, we use three classification methods i.e. SVM, Neural Network, and Naïve Bayes to find the best performance and optimal method to be used in credit quality detection for koperasi simpan pinjam. The process conducted by implementing pre-processing data using an SVM, Neural Network, and Naïve Bayes algorithm with the evaluation process using 5-fold cross validation. As the result, The Neural Network method was the best performing method. The average level of accuracy produced was $86.81 \%$, mean precision was 0.8194 , average recall was 0.8236 , and the average AUC value was 0.9158 . However, the execution time generated by the Neural Network algorithm made this algorithm the slowest algorithm compared to the other two methods. The average execution time of the Neural Network method was 3.058 seconds, longer than the other two algorithms which only range from 0 - 1 second.
\end{abstract}

Keywords: credit risk, classification, SVM, Neural Network, Nä̈ve Bayes

\section{PENDAHULUAN}

Kredit macet merupakan permasalahan utama yang dihadapi bagi mayoritas koperasi simpan pinjam di Indonesia. Proses pengajuan kredit di koperasi simpan pinjam sendiri terbilang lebih sederhana dibandingkan proses pengajuan kredit di bank, namun diperlukan sebuah analisis yang mendalam untuk menentukan diterima tidaknya pengajuan kredit dari nasabah guna meminimalisir adanya risiko kredit macet yang secara langsung akan berdampak pada profitabilitas dan kemampuan koperasi simpan pinjam itu sendiri untuk memberikan kredit selanjutnya.

Untuk meminimalisir adanya risiko kredit macet, pada umumnya terdapat seorang tenaga analis kredit yang bertugas untuk menganalisis kualitas pengajuan kredit yang dilakukan nasabah. Namun, mayoritas koperasi simpan pinjam di Indonesia tidak menggunakan tenaga analis kredit guna mengurangi 
pengeluaran perusahaan. Peran pengambil keputusan sekaligus penganalisis pengajuan kredit akan diambil oleh Pimpinan KSP, dengan proses yang dilakukan secara sederhana. Namun, tidak semua Pimpinan KSP mempunyai latar belakang sebagai analis kredit. Hal tersebut memungkinkan adanya kesalahan analisis kredit yang dapat menyebabkan risiko kredit (Sucipto, 2015).

Metode data mining yang dapat digunakan untuk memprediksi berdasarkan data masa lalu adalah klasifikasi (Larose, 2005). Metode klasifikasi yang digunakan dalam penelitian ini adalah Support Vector Machine (SVM), Neural Network, dan juga Naive Bayes. SVM adalah suatu teknik yang dirancang untuk menemukan hyperplane pemisah optimal yang memiliki margin maksimal (Gorunescu, 2011). Menurut Vapnik dan Cortes (1995) klasifikasi linier SVM dapat dihitung dengan Persamaan 1 dan 2.

$$
\begin{aligned}
& {\left[\left(\boldsymbol{w}^{T} \cdot \boldsymbol{x}_{i}\right)+b\right] \geq 1 \text { untuk } y_{i}=+1} \\
& {\left[\left(\boldsymbol{w}^{T} \cdot \boldsymbol{x}_{i}\right)+b\right] \leq-1 \text { untuk } y_{i}=-1}
\end{aligned}
$$

Untuk mengoptimasi Persamaan 1 dan 2 dapat diselesaikan menggunakan fungsi Lagrange Multiplier. Sedangkan untuk mencari hyperplane terbaik dapat digunakan metode Quadratic Programming (QP) Problem (Liao \& Triantaphyllou, 2007). Pada kasus non-linier, dapat digunakan metode kernel pada fitur data awal set data. Dengan kernel, dipetakan fitur data dari dimensi rendah ke fitur baru dengan dimensi yang relatif lebih tinggi (Prasetyo, 2014). SVM mempunyai kelebihan dimana proses training cukup dilakukan sekali saja sehingga tidak mengalami overfitting dan mendapatkan solusi optimal (Hidayatulloh, 2014).

Adapun Neural Network memperoleh nilai bobot untuk mentranformasikan nilai dari node input ke node output dari suatu algoritma pembelajaran tertentu. Pembaharuan nilai bobot secara umum dirumuskan pada Persamaan 3.

$$
w_{i j}(n+1)=w_{i j}(n)+\Delta w_{i j}(n)
$$

Dimana $\Delta w_{i j}(n)$ dihitung dengan algoritma pembelajaran dan $w_{i j}(n)$ merupakan bobot awal yang ditentukan secara acak pada tahap inisiasi (Gorunescu, 2011). Neural Network mampu menyelesaikan masalah-masalah yang sulit dan beragam karena metode ini mempunyai kemampuan fault tolerance sampai batas tertentu, sehingga metode ini tetap dapat menghasilkan keluaran meskipun data kurang lengkap (Raras, 2014).

Sedangkan algoritme Nä̈ve Bayes didasarkan pada asumsi penyederhanaan bahwa nilai atribut secara kondisional saling bebas jika diberikan nilai output (Ridwan, 2013). Naive Bayes mudah digunakan untuk menghitung fitur dengan data kategoris seperti pada kasus fitur "jenis kelamin" dengan nilai \{pria, wanita\} namun untuk fitur numerik terdapat pendekatan yang dilakukan sebelum dimasukkan kedalam Naive Bayes. (Wasiati \& Wijayanti, 2014). Sehingga terdapat perbedaan perhitungan nilai probabilitas (likelihood) untuk fitur numerik (kontinu) dan kategori (diskrit). Untuk fitur dengan atribut diskrit menggunakan Persamaan 4.

$$
P(H \mid X)=\frac{P(X \mid H) P(H)}{P(X)}
$$

Sedangkan untuk fitur dengan atribut kontinu dapat digunakan persamaan Gaussian yang tertera pada Persamaan 5.

$$
P\left(X_{i}=x_{i} \mid Y_{i}=x=y_{i}\right)=\frac{1}{\sqrt{2 \pi \sigma_{i j}}} \exp ^{\frac{\left(x_{i}-\mu_{i j}\right)}{2 \sigma_{i j}^{2}}}
$$

Naive Bayes mampu melakukan proses training dengan waktu komputasi yang cepat dan juga mampu meningkatkan performa klasifikasi dengan menghilangkan fitur-fitur yang tidak relevan (Jadhav \& Channe, 2014).

Terdapat beberapa penelitian terdahulu, seperti pada penelitian yang dilakukan oleh Mittal et. al. (2016), dimana dalam penelitian ini digunakan tiga metode yaitu SVM, Neural Network, dan juga Naive Bayes untuk menentukan algoritme yang paling optimal dan akurat utuk memprediksi risiko kredit guna membantu manajemen bank mengurangi kerugian dengan melakukan proses pengambilan keputusan yang tepat. Pada penelitian ini SVM diimplementasikan menggunakan polynomial kernel dengan parameter degree bernilai 3, gamma bernilai 2,6, 2,5, dan 3,2, serta nilai coef adalah 100, Neural Network diimplementasikan dengan iterasi sebanyak 500, nilai momentum constant sebesar 0,7, learning rate sebesar 0,1, dan hidden layer sebanyak 5, sedangkan Naive Bayes diimplementasikan dengan sekali proses. Hasil yang didapatkan adalah SVM menghasilkan tingkat akurasi tertinggi sebesar 92\%, diikuti Naive Bayes sebesar $87 \%$, dan Neural Network menghasilkan tingkat akurasi terendah sebesar $85 \%$. Penelitian kedua merupakan penelitian yang dilakukan oleh Chakraborti (2014), dimana dalam penelitian ini menggunakan metode Naive Bayes, Decision Tree, SVM, Bayesian Network, dan Neural Network yang dibandingkan guna menemukan algoritme yang optimal dan akurat untuk memprediksi kelas gaji dari karyawan. 10-fold cross validation diimplementasikan pada semua algoritme yang digunakan pada penelitian ini, sedangkan khusus untuk SVM diimplementasikan menggunakan polykernel dengan nilai eksponen sebesar 1, chaceSize sebesar 250007, complexity constant sebesar 1, dan epsilon sebesar 1.0E-12, sedangkan untuk Neural Network diimplementasikan dengan nilai iterasi sebanyak 500 kali, learning rate sebesar 0,3 , momentum constant sebesar 0,2 , dan terdiri dari 54 node, satu hidden layer, satu input dan output layer. Hasil yang didapatkan, SVM menghasilkan tingkat akurasi tertinggi dengan 84,9022\%, kemudian 
Naive Bayes menghasilkan 83,428\%, dan Neural Network menghasilkan tingkat akurasi terendah dibanding SVM dan Naive Bayes sebesar 82,8936\%.

Berdasarkan paparan yang telah dijabarkan, penelitian ini bertujuan untuk membandingkan tiga algoritme yang digunakan yaitu SVM, Neural Network, dan juga algoritme Naive Bayes guna mendapatkan algoritme dengan tingkat performa paling baik untuk menyediakan sistem yang mampu mendukung pihak manajerial KSP dalam mendeteksi kualitas kredit sejak dini.

\section{METODE PENELITIAN}

Metode penelitian yang digunakan dalam penelitian ini terpapar pada Gambar 1 .

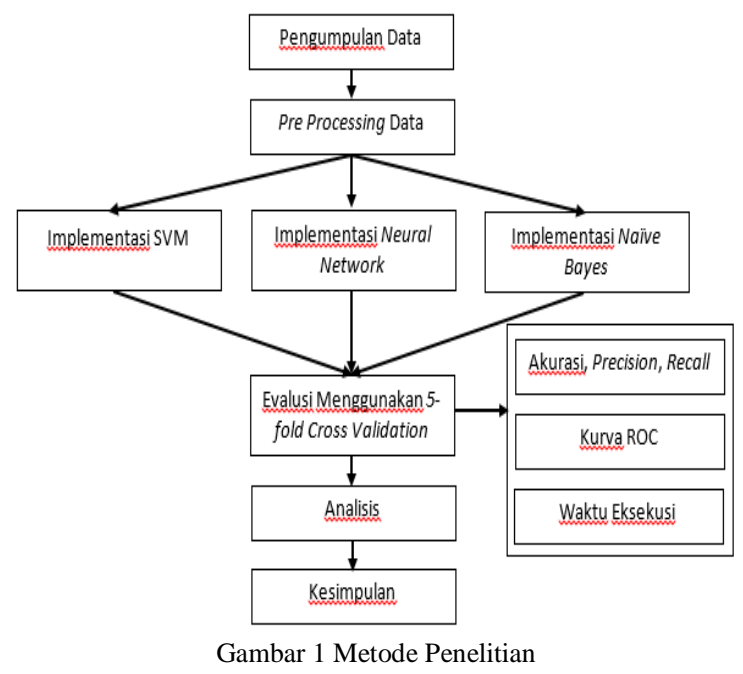

\subsection{Pengumpulan Data}

Tahap pertama adalah pengumpulan data dari salah satu KSP. Data yang terkumpul adalah data pinjaman nasabah terdahulu berjumlah 193 data dalam kurun waktu bulan Oktober sampai Desember 2017 dan Januari 2018 yang memiliki label kelas lancar dan macet.

\subsection{Pre-Processing Data}

Sebelum dilakukan proses klasifikasi, dilakukan pre-processing terhadap dataset yang telah terkumpul. Ada tiga tahap yang dilakukan pada preprocessing data, yaitu data selection, data cleansing, dan data transformation. Data selection digunakan untuk memilih parameter yang nantinya berperan sebagai predictor dalam proses klasifikasi. Dari dataset yang telah terkumpul, terdapat 13 atribut yang melekat pada dataset, yaitu nama anggota, jenis kelamin, alamat, pekerjaan, total pinjaman, waktu angsuran, tipe agunan, jumlah tanggungan, status pernikahan, bunga pokok (6 bulan), pendapatan utama, total biaya hidup, dan status pinjaman. Namun, tidak semua parameter tersebut akan digunakan pada penelitian ini. Proses pemilihan parameter yang digunakan pada penilitan ini didasarkan dari pendapat Pimpinan KSP, dimana parameter-parameter yang terpilih berdampak langsung terhadap macet tidaknya pinjaman nasabah. Data cleansing digunakan untuk menghilangkan missing value yang terdapat pada dataset, sehingga dihasilkan data yang benar-benar bersih dan siap untuk digunakan dalam proses klasifikasi. Missing values dari dataset yang terkumpul berupa data dengan parameter bernilai kosong. Proses data cleansing dilakukan dengan cara menghapus baris data yang mengandung missing values. Data transformation digunakan untuk mengubah nilai dari parameter menjadi bentuk nilai terkategori dan juga mengubah nama parameter menjadi bentuk snake case style untuk memudahkan proses klasifikasi menggunakan Weka. Proses data transformation yang digunakan adalah generalization dan attribute construction. Generalization digunakan untuk merubah nilai-nilai acak dari dataset yang terkumpul menjadi bentuk nilai-nilai yang terkategori, sedangkan attribute construction digunakan untuk merubah atribut dari dataset yang terkumpul menjadi bentuk atribut dalam bentuk snake case style yang akan memudahkan proses klasifikasi. Penentuan nilai kategori yang digunakan didasarkan pada pendapat Pimpinan KSP. Hasil dari pre-processing data didapatkan 185 data dengan parameter dan nilai yang tertera pada Tabel 1 .

Tabel 1 Parameter dan Nilai Hasil Pre Processing Data

\begin{tabular}{|c|c|c|}
\hline No & Parameter & Nilai \\
\hline 1 & JENIS_KELAMIN & $\begin{array}{c}\text { PRIA (L) } \\
\text { WANITA (P) }\end{array}$ \\
\hline 2 & TOTAL_PINJAMAN & $\begin{array}{c}\text { SANGAT_RENDAH } \\
\text { RENDAH } \\
\text { SEDANG } \\
\text { TINGGI } \\
\text { SANGAT_TINGGI }\end{array}$ \\
\hline 3 & $\begin{array}{c}\text { JUMLAH_TANGGU } \\
\text { NGAN }\end{array}$ & $\begin{array}{l}\text { SEDIKIT } \\
\text { SEDANG } \\
\text { BANYAK }\end{array}$ \\
\hline 4 & $\begin{array}{c}\text { STATUS_PERNIKAH } \\
\text { AN }\end{array}$ & $\begin{array}{c}\text { MENIKAH } \\
\text { BELUM_MENIKAH } \\
\text { CERAI }\end{array}$ \\
\hline 5 & $\begin{array}{c}\text { PENDAPATAN_UTA } \\
\text { MA }\end{array}$ & $\begin{array}{c}\text { RENDAH } \\
\text { SEDANG } \\
\text { TINGGI }\end{array}$ \\
\hline 6 & $\begin{array}{c}\text { TOTAL_BIAYA_HID } \\
\text { UP }\end{array}$ & $\begin{array}{c}\text { RENDAH } \\
\text { SEDANG } \\
\text { TINGGI }\end{array}$ \\
\hline 7 & STATUS_PINJAMAN & $\begin{array}{c}\text { LANCAR } \\
\text { MACET }\end{array}$ \\
\hline
\end{tabular}

\subsection{Implementasi dan Evaluasi}

Dari hasil pre-processing data, selanjutnya dilakukan implementasi menggunakan ketiga metode yang digunakan, yaitu SVM dengan parameter complexity constant sebesar 1, epsilon sebesar 1.0E12 , kernel yang digunakan adalah polykernel dengan nilai eksponen sebesar 1 dan chacedSize sebesar 250007, Neural Network dengan parameter learning rate sebesar 0,3, momentum constant sebesar 0,2, iterasi sebanyak 500 kali, dan 10 hidden layer 
((jumlah atribut + jumlah kelas)/2), dan juga Naive Bayes menggunakan tool Weka. Pemilihan parameter didasarkan pada pemilihan terbaik yang dilakukan oleh Weka sebagai tool pendukung pada penilitian ini. Implementasi ketiga metode yang digunakan dipadukan dengan pengevaluasian menggunakan 5fold cross validation, sehingga akan didapatkan tingkat akurasi, precision, recall, nilai ROC/AUC, dan juga waktu eksekusi dari ketiga metode dengan training set dan testing set yang terus dirotasi.

\subsection{Analisis dan Kesimpulan}

Hasil dari evaluasi menggunakan 5-fold cross validation, selanjutnya akan dianalisa dalam hal perbandingan performa dari ketiga algoritme yang digunakan untuk mendapatkan algoritme yang akurat dan optimal dalam proses pendeteksian pengajuan kredit pada KSP. Langkah selanjutnya adalah menarik kesimpulan dari penelitian yang telah dilakukan.

\section{HASIL DAN PEMBAHASAN}

Hasil akhir yang didapatkan tertera pada Tabel 2. Dari ketiga algoritme, secara keseluruhan Neural Network memiliki rerata tingkat akurasi tertinggi dibanding dua algoritme lain dengan rerata nilai akurasi sebesar $86,81 \%$, sedangkan algoritme SVM menghasilkan rerata nilai akurasi sebesar $85,62 \%$ dan Naive Bayes menjadi algoritme dengan rerata nilai akurasi terendah dengan nilai rerata sebesar 83,24\%. Rerata tingkat akurasi dari ketiga algoritme yang digunakan tertera dalam Gambar 2.

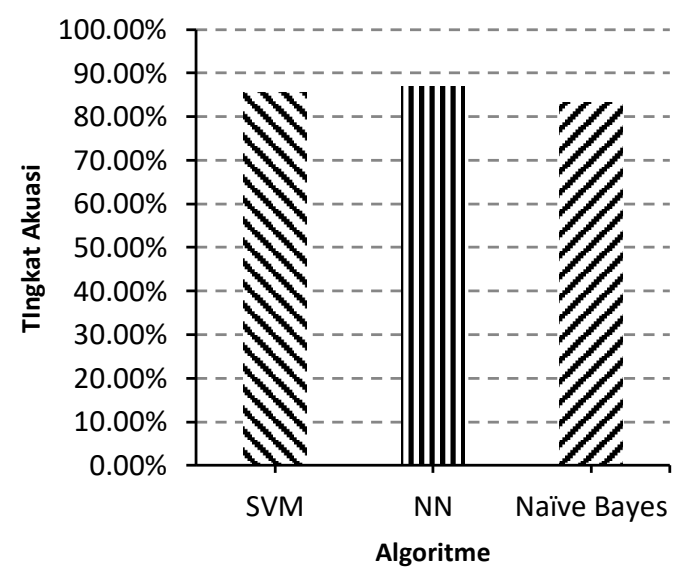

Gambar 2 Perbandingan Rerata Tingkat Akurasi

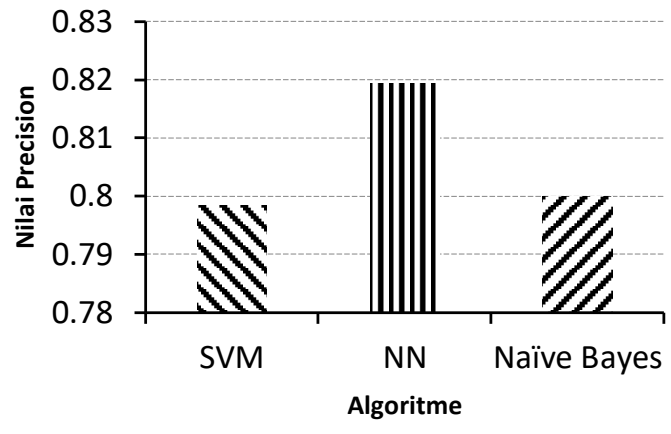

Gambar 3 Perbandingan Rerata Precision

Precision yang dihasilkan dari ketiga algoritme direpresentasikan dalam Gambar 3. Neural Network menghasilkan rerata nilai precision paling baik dibanding dua metode lain dengan nilai rerata sebesar 0,8194. Naive Bayes menghasilkan rerata nilai precision sebesar 0,8 dan SVM menghasilkan rerata nilai precision terendah dengan nilai 0,7984 .

Rerata nilai recall dari ketiga algoritme yang digunakan tertera pada Gambar 4. Rerata nilai recall tertinggi dari ketiga algoritme yang digunakan adalah sebesar 0,8236 yang dihasilkan oleh algoritme Neural Network. SVM menghasilkan nilai rerata 0,8146 dan Naive Bayes menghasilkan nilai rerata recall terkecil dengan nilai sebesar 0,7264 .

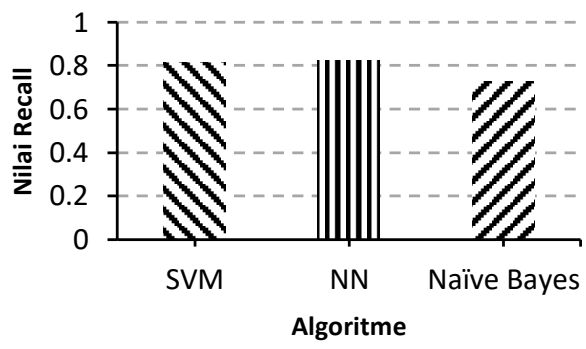

Gambar 4 Perbandingan Rerata Recall

Untuk nilai AUC dari ketiga algoritme yang digunakan tertera dalam Gambar 5. Dimana, algoritme Neural Network memperoleh nilai rerata AUC paling baik dibanding dua metode lain dengan nilai rerata sebesar 0,9158, dimana menurut Gorunescu (2011), Neural Network termasuk klasifikasi yang sangat baik dalam penelitian ini. Nilai rerata AUC untuk algoritme SVM menghasilkan nilai 0,8476 dan Naive Bayes menghasilkan nilai 0,8986, sehingga menurut Gorunescu (2011), keduanya termasuk ke dalam golongan klasifikasi baik dalam penelitian ini.

Tabel 2 Hasil Akhir

\begin{tabular}{cccccc}
\hline Algoritme & $\begin{array}{c}\text { Akurasi } \\
(\boldsymbol{\%})\end{array}$ & Precision & Recall & AUC & Waktu Eksekusi (s) \\
\hline SVM & 85,6216 & 0,7984 & 0,8146 & 0,8476 & 0,914 \\
Neural Network & 86,8108 & 0,8194 & 0,8236 & 0,9158 & 3,058 \\
Naïve Bayes & 83,2432 & 0,8 & 0,7264 & 0,8986 & 0,01 \\
\hline
\end{tabular}




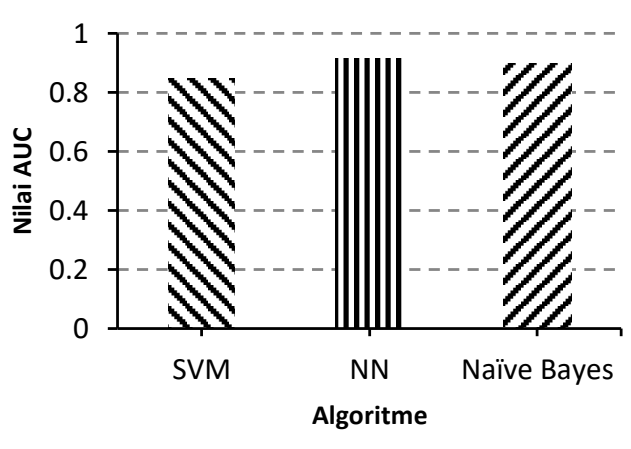

Gambar 5 Perbandingan Rerata AUC

Algoritme Neural Network menjadi algoritme paling baik diantara dua algoritme lainnya dalam penelitian ini. Merujuk dari tahapan proses klasifikasi yang dilakukan Neural Network, terdapat proses iterasi yang berulang-ulang, dimana tiap iterasi akan dilakukan pembaruan setiap weight dan bias pada tiap neuron secara terus-menerus hingga didapatkan nilai performa terbaik (Fredenslund, 2018). Hal tersebut dapat dijadikan asumsi yang mendasari Neural Network mampu menghasilkan tingkat performa paling optimal dibanding dua algoritme lainnya.

Sedangkan waktu eksekusi dari ketiga algoritme yang digunakan tertera dalam Gambar 6. Dimana, waktu eksekusi untuk algoritme SVM mengalami fluktuasi pada kisaran waktu lebih dari 0,1 detik hingga kurang dari 0,3 detik. Untuk algoritme Neural Network memiliki waktu eksekusi paling lambat di antara dua algoritme lain, dimana Neural Network juga mengalami fluktuasi pada kisaran waktu lebih dari 3 detik, sedangkan Naive Bayes merupakan algoritme dengan waktu eksekusi tercepat di antara dua algoritme lain. Waktu eksekusi Naive Bayes stagnan dari fold ke-1 sampai fold ke-5 dengan waktu eksekusi sebesar 0,01 detik.

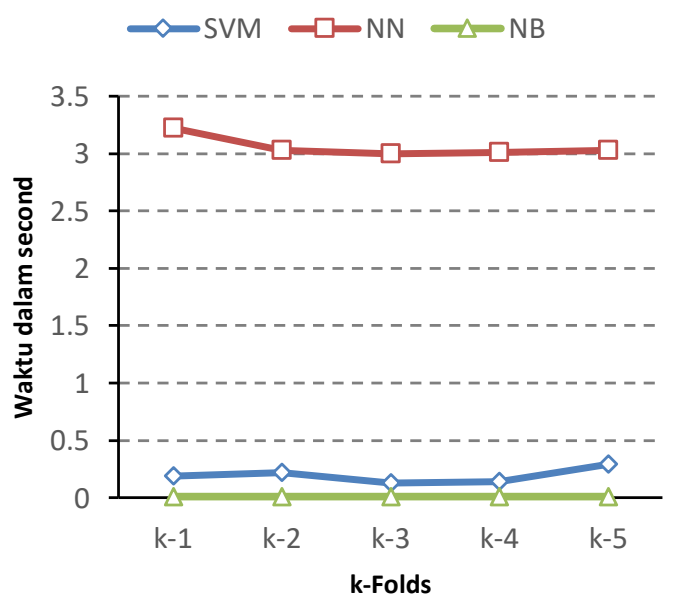

Gambar 6 Waktu Eksekusi Tiga Algoritme

Naive Bayes menjadi algoritme paling cepat dalam melakukan proses klasifikasi, sedangkan Neural Network menjadi algoritme paling lambat dalam melakukan proses klasifikasi dalam penelitian ini. Tahapan klasifikasi pada algoritme Naive Bayes lebih sederhana dibandingkan dengan tahapan algoritme SVM dan Neural Network, sehingga waktu eksekusi yang dilakukan jauh lebih cepat dibandingkan dengan dua algoritme lain (Jadhav \& Channe, 2016). Sedangkan pada Neural Network, dilakukan proses iterasi sebanyak 500 kali pada tahapan klasifikasinya, sehingga akan menghasilkan waktu eksekusi yang cukup lama (Fredenslund, 2018). Hal ini juga menjadi salah satu kelemahan dari algoritme Neural Network ini.

\section{KESIMPULAN}

Dari penelitian yang telah dilakukan, dapat ditarik kesimpulan bahwa untuk proses pendeteksian kualitas kredit dengan menggunakan 185 data hasil dari pre processing data, dimana parameter yang digunakan pada penelitian ini didasarkan pada pendapat Pimpinan KSP, algoritme Neural Network mempunyai tingkat akurasi, precision, recall, dan nilai AUC terbaik dibandingkan dengan metode klasifikasi lain yang digunakan pada penelitian ini, yaitu SVM dan Nä̈ve Bayes dengan rerata tingkat akurasi $86,81 \%$, precision 0,8194 , recall 0,8236 , dan nilai AUC 0,9158, sehingga yang tergolong sebagai klasifikasi paling baik untuk pendeteksian kualitas kredit pada proses pengajuan pinjaman di koperasi simpan pinjam menurut Gorunescu (2011) adalah Neural Network. Namun, Neural Network menjadi metode dengan waktu eksekusi paling lambat apabila dibandingkan dengan dua metode lain. Nilai rerata waktu eksekusi dari metode Neural Network sebesar 3,058 detik, jauh lebih lama dibandingkan dua metode lain yang berkisar pada nilai $0-1$ detik. Terdapat proses iterasi pada tahapan klasifikasi dari algoritme Neural Network, dimana pada setiap iterasi dilakukan pembaruan weight dan bias pada tiap neuron secara terus-menerus hingga didapatkan nilai performa terbaik. Hal tersebut dapat menjadi asumsi algoritme ini mampu menghasilkan tingkat performa paling baik dalam penelitian ini. Namun, dengan adanya proses iterasi tersebut, menjadikan Neural Network sebagai algoritme paling lambat dalam penelitian ini.

\section{DAFTAR PUSTAKA}

CHAKRABORTI, S., 2014. A Comparative Study of Performances of Various Classification Algorithms for Predicting Salary Classes of Employees. International Journal of Computer Science and Information Technologies. Vol. 5 No. 2.

FREDENSLUND, K., 2018. Computational Complexity of Neural Networks. [online] Tersedia di: $<$ https://kasperfred.com/posts/computationa l-complexity-of-neural-networks> [Diakses pada 8 Agustus 2018]. 
GORUNESCU, F., 2011. Data Mining: Concept, Models, and Techniques. Verlag Berlin Heidelberg: Springer.

HIDAYATULLOH, T., 2014. Kajian Komparasi Penerapan Algoritma Support Vector Machine (SVM) dan Multilayer Perceptron (MLP) dalam Prediksi Indeks Saham Sektor Perbankan: Studi Kasus Saham LQ45 IDX Bank BCA. [online] Tersedia di: < https://www.researchgate.net/publication/2 64899064> [Diakses pada: 13 Agustus 2018].

JADHAV, S. D. \& CHANNE, H. P., 2016. Comparative Study of k-NN, Naïve Bayes, and Decision Tree Classification Techniques. International Journal of Science and Researches. Vol 5 Issue 1.

LAROSE, T. D., 2005. Discovering Knowledge in Data. New Jersey: Jhon Willey \& Sons, Inc.

LIAO, W. T. \& TRIANTAPHYLLOU, E., 2007. Recent Advances in Data Mining of Enterprise Data: Algorithms and Applications, Series on Computers and Operations Research. Vol 6. Singapore: World Scientific Publishing Co. Pte. Ltd.

MITTAL, L., GUPTA, T., \& SANGAIAH, A. K., 2016. Prediciton of Credit Risk Evaluation Using Naïve Bayes, Artificial Neural Network, and Support Vector Machine. The IIOAB Journal.

VAPNIK, V., \& CORTES, C., 1995. Support-Vector Networks. Boston: Kluwer Academic Publishers. 20, pp. 273-297.

PRASETYO, E., 2014. Data Mining Mengolah Data Menjadi Infromasi Menggunakan Matlab. Yogyakarta: Andi.

RARAS, B., 2014. Prediksi Data Menggunakan Neural Network dengan Algorithma Backpropagation. [online] Tersedia di: < https://www.academia.edu/7382142/Predik si_Data_Menggunakan_Neural_Network_d engan_Algorithma_Backpropagation> [Diakses pada: 13 Agustus 2018].

RIDWAN, M., et. al., 2013. Penerapan Data Mining untuk Evaluasi Kinerja Akademik Mahasiswa Menggunakan Algoritma Naïve Bayes Classifier. Jurnal EECCIS. Vol. 7 No. 1.

SUCIPTO, A., 2015. Prediksi Kredit Macet Melalui Perilaku Nasabah pada Koperasi Simpan Pinjam dengan Menggunakan Metode Algoritma Klasifikasi C4.5. Jurnal DISPROTEK.

WASIATI, H., \& WIJAYANTI, D., 2014. Sistem Pendukung Keputusan Penentuan Kelayakan Calon Tenaga Kerja Indonesia Menggunakan Metode Naïve Bayes (Studi Kasus: Di P.T. Karyatama Mitra Sejati
Yogyakarta). Indonesia Journal of Network \& Security. Vol. 3 No. 2. 